\title{
Social Networks Are Associated with Healthcare Utilization Among Taxi and For-Hire Vehicle Drivers: a Latent Class Analysis
}

\author{
Devika R. Jutagir, $P h D^{7}$, Imran Mujawar, $M S^{7}$, Soo Young Kim, $M A^{7}$, \\ Andrew Rasmussen, $\mathrm{PhD}^{2}$, Bharat Narang, $\mathrm{MPH}^{7}$, and Francesca Gany, $\mathrm{MD}, \mathrm{MS}^{7}$ (B) \\ 'Department of Psychiatry and Behavioral Sciences, Memorial Sloan Kettering Cancer Center, New York, NY, USA; ${ }^{2}$ Department of Psychology, \\ Fordham University, New York, NY, USA.
}

J Gen Intern Med 35(5):1593-6

DOI: $10.1007 / \mathrm{s} 11606-019-05456-\mathrm{y}$

(c) Society of General Internal Medicine 2019

\section{INTRODUCTION}

Taxi and for-hire vehicle (FHV) driving is a growing occupation, with over 185,000 licensed taxi/FHV drivers in New York City (NYC) alone and well over 300,000 in the USA. ${ }^{1,}$ ${ }^{2}$ Most licensed NYC drivers have racial/ethnic minority backgrounds and are authorized immigrants. ${ }^{1}$ Because of their sedentary occupation, poor diet, pollution exposure, discrimination, stressors, and ethnic backgrounds, drivers are at an elevated risk for cardiovascular disease (CVD), cancer, hypertension, obesity, and diabetes. ${ }^{3}$

Most NYC drivers are independent contractors without workplace-sponsored health insurance. ${ }^{1,3}$ Hence, many are uninsured (34\% in a recent study) and lack a primary care provider (PCP). ${ }^{3}$ According to Andersen's widely acknowledged behavioral model of health services use, social context predisposes individuals to use services or not. ${ }^{4}$ In low socioeconomic status and immigrant populations, social networks are important conduits for health information. ${ }^{5}$ Subgroups of medically underserved ethnic minority individuals share healthcare utilization habits, ${ }^{6}$ and it is likely that the heterogeneous taxi/FHV driver population can be classified according to at least three healthcare utilization profiles. ${ }^{6}$ This is the first study to test whether social networks relate to healthcare utilization profiles in taxi/FHV drivers.

\section{METHODS}

An Institutional Review Board-exempted, cross-sectional needs assessment was conducted with NYC taxi/FHV drivers from March 2013 to April 2014, assessing demographics; healthcare access and utilization (having health insurance, a PCP, a past-

The results have previously been presented at the Society of Behavioral Medicine's 40th Annual Meeting.

Received July 9, 2019

Accepted September 27, 2019

Published online November 8, 2019 year routine checkup, and dental visit); and drivers' social networks, by asking with whom ("alters") the driver ("ego") had discussed health-related advice over the past year.

Latent class analysis grouped drivers by their healthcare access and utilization patterns. Descriptive egocentric social network analysis tested whether driver healthcare access and utilization patterns related to their social network characteristics. Bivariate associations between social network variables or demographic covariates with latent class membership were tested, and social network variables and covariates were included in the multivariable model, based on statistically significant associations with latent class membership.

\section{RESULTS}

Table 1 describes the 211 participants and shows each latent class's healthcare access and utilization item response probabilities. Model-fit diagnostics identified three latent classes: "uninsured past-year non-utilizers" (lowest item response probabilities for all items), "insured past-year utilizers" (high item response probabilities for having health insurance and past-year PCP visit), and "uninsured past-year utilizers" (lower item response probabilities for health insurance and PCP, high probabilities for past-year PCP and dental visits).

Medical and dental past-year checkups were more probable among uninsured past-year utilizers $(99.0 \%$ and $83.5 \%$, respectively) than insured past-year utilizers ( $91.3 \%$ and $57.6 \%$ ) and past-year non-utilizers (22.5\% and 20.5\%).

Drivers with a large proportion of their network providing health advice were more likely to be uninsured past-year utilizers than uninsured past-year non-utilizers (Table 2). No other variables related to class membership in multivariable regression.

\section{DISCUSSION}

The results support prior studies showing high- and low-use primary care access and utilization classes in immigrants. ${ }^{6}$ In addition to low PCP uptake rates, low dental visit rates were concerning, given the connection between poor dental health and CVD risk, coupled with drivers' other risk factors. ${ }^{3}$ However, a 
Table 1 Sample Descriptives $(N=211)$

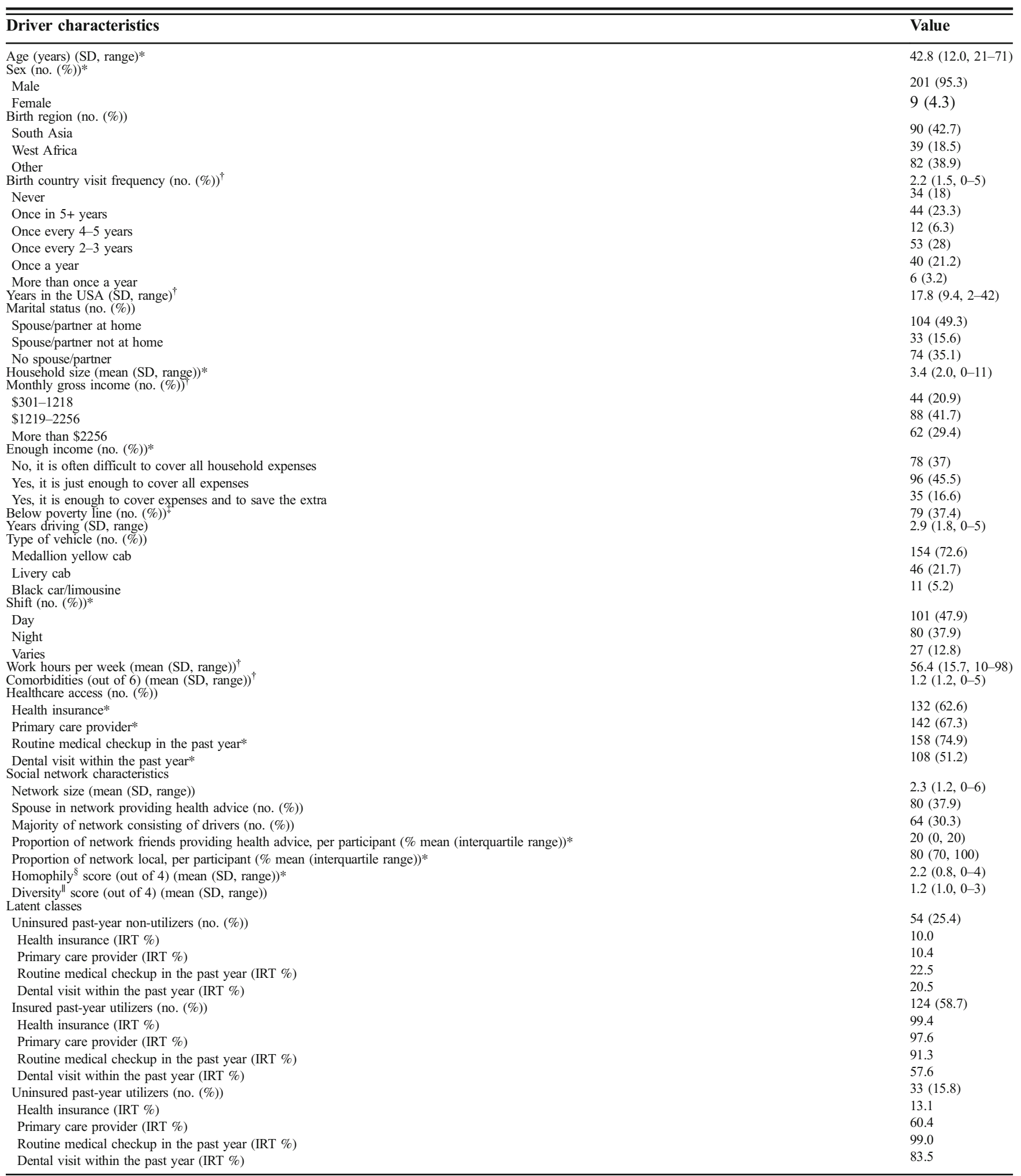

Abbreviations: $S D$, standard deviation; IRT, item response probability

$*<4 \%$ data missing $(n=1-7)$

$\$ 19 \%$ data missing $(n=40)$

${ }_{{ }_{1}}$ Homophily score defined as extent to which drivers matched alters with respect to gender, age (age difference $\leq 5$ years), language, and taxi/for-hire vehicle driver profession "Diversity score calculated as the average number of differences (out of 4) between each alter-alter dyad with respect to gender, age (age difference $\leq 5$ years), language, and occupation. Drivers with $<2$ alters had a diversity score of 0 
Table 2 Multinomial Logistic Regression Modeling Membership Probability of Being in the "Uninsured Past-Year Utilizers" or in the "Insured Past-Year Utilizers" Class in Reference to the "Uninsured Past-Year Non-Utilizers" Class

\begin{tabular}{|c|c|c|c|}
\hline Variable & $\begin{array}{l}\text { Latent class } \\
\text { (ref: uninsured past-year non-utilizers) }\end{array}$ & $\begin{array}{l}\text { Bivariate } \\
\text { OR }(95 \% \text { CI })\end{array}$ & $\begin{array}{l}\text { Multivariable } \\
\text { OR (95\% CI) }\end{array}$ \\
\hline Age & $\begin{array}{l}\text { Uninsured utilizer } \\
\text { Insured utilizer }\end{array}$ & $\begin{array}{l}1.04(1.00,1.08) \\
1.05(1.02,1.08)^{\ddagger}\end{array}$ & $\begin{array}{l}0.95(0.87,1.05) \\
1.02(0.95,1.10)\end{array}$ \\
\hline \multicolumn{4}{|l|}{ Region (ref: others) } \\
\hline South Asia & Uninsured utilizer & $0.67(0.23,1.94)$ & $0.30(0.06,1.52)$ \\
\hline South Asia & Insured utilizer & $0.89(0.42,1.89)$ & $1.11(0.31,3.96)$ \\
\hline West Africa & Uninsured utilizer & $0.80(0.26,2.44)$ & $0.85(0.18,3.99)$ \\
\hline West Africa & Insured utilizer & $0.30(0.12,0.73)^{\dagger}$ & $0.31(0.08,1.17)$ \\
\hline Birth country visit frequency & Uninsured utilizer & $1.33(1.05,1.67)^{*}$ & $1.34(0.90,2.00)$ \\
\hline Years in the USA & $\begin{array}{l}\text { Insured utilizer } \\
\text { Uninsured utilizer }\end{array}$ & $\begin{array}{l}1.43(1.04,1.95)^{*} \\
1.09(1.05,1.14)^{\ddagger} \\
1.07(101113)^{*}\end{array}$ & $\begin{array}{l}1.22(0.90,1.66) \\
1.06(0.95,1.17)\end{array}$ \\
\hline \multicolumn{4}{|l|}{ Marital status (ref: no. spouse/partner) } \\
\hline Spouse/partner home & Uninsured utilizer & $2.38(0.88,6.43)$ & $2.07(0.42,10.31)$ \\
\hline Spouse/partner home & Insured utilizer & $3.57(1.66,7.67)^{\dagger}$ & $1.61(0.45,5.81)$ \\
\hline Spouse/partner not home & Uninsured utilizer & $0.52(0.12,2.20)$ & $0.29(0.04,2.0)$ \\
\hline Spouse/partner not home & Insured utilizer & $1.01(0.42,2.47)$ & $1.02(0.25,4.17)$ \\
\hline \multirow[t]{2}{*}{ Household size } & Uninsured utilizer & $1.27(1.00,1.61) *$ & $1.04(0.72,1.51)$ \\
\hline & Insured utilizer & $1.31(1.09,1.57)^{\dagger}$ & $1.16(0.85,1.57)$ \\
\hline \multicolumn{4}{|l|}{ Enough income (ref: enough) } \\
\hline Not enough for expenses & Uninsured utilizer & $0.69(0.20,2.35)$ & $0.26(0.04,1.51)$ \\
\hline Not enough for expenses & Insured utilizer & $2.87(1.05,7.82)^{*}$ & $3.77(0.75,18.93)$ \\
\hline Just enough for expenses & Uninsured utilizer & $0.44(0.15,1.35)$ & $0.20(0.04,1.01)$ \\
\hline Just enough for expenses & Insured utilizer & $1.41(0.56,3.54)$ & $1.45(0.32,6.65)$ \\
\hline \multirow{2}{*}{ Years driving } & Uninsured utilizer & $1.48(1.13,1.94)^{\dagger}$ & $1.44(0.84,2.47)$ \\
\hline & Insured utilizer & $1.42(1.17,1.74)^{\ddagger}$ & $0.93(0.61,1.44)$ \\
\hline \multicolumn{4}{|l|}{ Shift (ref: day) } \\
\hline Night & Uninsured utilizer & $0.63(0.24,1.66)$ & $0.72(0.20,2.57)$ \\
\hline Night & Insured utilizer & $0.45(0.23,0.91)^{*}$ & $0.48(0.18,1.28)$ \\
\hline Varied & Uninsured utilizer & $3.57(0.60,21.1)$ & $5.05(0.44,57.72)$ \\
\hline Varied & Insured utilizer & $2.99(0.64,13.9)$ & $2.74(0.28,26.57)$ \\
\hline \multirow[t]{2}{*}{ Number of comorbidities } & Uninsured utilizer & $1.44(0.90,2.32)$ & $1.32(0.67,2.60)$ \\
\hline & Insured utilizer & $2.05(1.40,2.99)^{\ddagger}$ & $1.42(0.84,2.42)$ \\
\hline \multirow{3}{*}{$\begin{array}{l}\text { Social network characteristics } \\
\text { Proportion of network providing health advice }\end{array}$} & & & \\
\hline & Uninsured utilizer & $5.20(1.18,23.0)^{*}$ & $9.52(1.43,63.56)^{*}$ \\
\hline & Insured utilizer & $1.67(0.46,6.01)$ & $1.98(0.36,10.93)$ \\
\hline \multirow[t]{2}{*}{ Proportion of network local } & Uninsured utilizer & $1.28(0.34,4.82)$ & $0.49(0.08,3.07)$ \\
\hline & Insured utilizer & $3.79(1.33,10.8)^{*}$ & $2.28(0.53,9.78)$ \\
\hline
\end{tabular}

Only variables that reached significance were included in the multivariable model Abbreviations: CI, confidence interval; OR (95\% CI), odds ratio ${ }^{*} p<0.05 ;{ }^{*} p<0.01 ;{ }^{*} p<0.001$

latent class emerged (uninsured past-year utilizers) that sought routine PCP and dental checkups despite lacking regular PCPs or health insurance. Drivers were more likely to be in this class than in the uninsured past-year non-utilizers class if they reported a larger proportion of friends providing health advice.

Demographic characteristics typically associated with healthcare access and utilization (e.g., years in the USA, marital and socioeconomic statuses) did not relate to latent classes in the multivariable model, supporting a heightened need for tailored targeted interventions, such as drivers trained to provide health advice, to promote healthcare access among taxi/FHV drivers. These interventions could enhance connections to insurance, primary care, and annual medical and dental appointments for drivers lacking friends providing health advice.

Future studies could inform interventions by investigating non-insurance factors; motivations for dental and PCP visits among uninsured past-year utilizers; the nature of alters' health advice; drivers' usage of other health advice sources, e.g., online; and healthcare utilization processes among the growing numbers of app-based FHV drivers. ${ }^{1,2}$

This study identified a latent class of uninsured taxi/FHV drivers with a high proportion of friends giving health advice and probability of dental and PCP usage, suggesting that social networks could be leveraged to facilitate healthcare utilization in this vulnerable population.

Acknowledgments: The authors would like to thank Sonya Smyk, Memorial Sloan Kettering Cancer Center, for editorial support. She was not compensated beyond her regular salary.

Corresponding Author: Francesca Gany, MD, MS; Department of Psychiatry and Behavioral SciencesMemorial Sloan Kettering Cancer Center, New York , NY, USA (e-mail: ganyf@mskcc.org).

Author Contributions I.M., A.R., and F.G. conceived the idea for the manuscript. F.G. oversaw data collection. I.M., S.K., B.N., D.J., and F.G. contributed to data analysis. D.J., I.M., A.R., S.K., and F.G. interpreted the results. D.J. took the lead on writing the article with assistance from I.M. and F.G. and input from A.R. and S.K. 
Funding Information This study was supported by the following: P30: National Cancer Institute (P30 CA008748), T32: National Cancer Institute (T32 CA00946), U01: National Center on Minority Health and Health Disparities (UO1 MD010648), R01: National Institute of Nursing Research (RO1 NR015265), R24: National Center on Minority Health and Health Disparities (R24 MD008058).

\section{Compliance with Ethical Standards:}

Memorial Sloan Kettering Cancer Center Institutional Review Board protocol no. for this study is X13-008 (exempt status).

Conflict of Interest: The authors declare that they have no conflict of interest.

\section{REFERENCES}

1. New York City Taxi and Limousine Commission. Taxicab Factbook 2018. 2018; https://www1.nyc.gov/assets/tlc/downloads/pdf/2018_tlc factbook.pdf. Accessed 19 August 2019.
2. Bureau of Labor Statistics, United States Department of Labor. Taxi Drivers and Chauffers. 2017; https://www.bls.gov/ooh/transportationand-material-moving/home.htm. Accessed 15 January 2019.

3. Mirpuri S, Gill P, Ocampo A, et al. Discrimination and health among taxi drivers in New York and Toronto. J Community Health 2018;43(4):667672.

4. Andersen RL, Davidson P. Improving access to care in America: Individual and contextual indicators. Changing the U.S. health care system: Key issues in health services policy and management. San Francisco: JosseyBass; 2007:3-31.

5. Kim W, Kreps GL, Shin CN. The role of social support and social networks in health information-seeking behavior among Korean Americans: a qualitative study. Int J Equity Health. 2015;14:40

6. Jang Y, Park NS, Yoon H, et al. The risk typology of healthcare access and its association with unmet healthcare needs in Asian Americans. Health Soc Care Community 2018;26(1):72-79.

Publisher's Note Springer Nature remains neutral with regard to jurisdictional claims in published maps and institutional affiliations. 